\title{
Action Embellishment: An Intention Bias in the Perception of Success
}

\section{Citation}

Preston, Jesse Lee, Ryan S. Ritter, and Daniel M. Wegner. 2011. Action embellishment: An intention bias in the perception of success. Journal of Personality and Social Psychology 101(2): 233-244.

\section{Published Version}

doi:10.1037/a0023231

\section{Permanent link}

http://nrs.harvard.edu/urn-3:HUL.InstRepos:9925389

\section{Terms of Use}

This article was downloaded from Harvard University's DASH repository, and is made available under the terms and conditions applicable to Open Access Policy Articles, as set forth at http:// nrs.harvard.edu/urn-3:HUL.InstRepos:dash.current.terms-of-use\#OAP

\section{Share Your Story}

The Harvard community has made this article openly available.

Please share how this access benefits you. Submit a story.

\section{Accessibility}




\title{
RUNNING HEAD: ACTION EMBELLISHMENT
}

\author{
Action Embellishment: \\ An Intention Bias in the Perception of Success \\ Jesse Lee Preston \& Ryan S. Ritter \\ University of Illinois at Urbana-Champaign \\ Daniel M. Wegner \\ Harvard University
}

First submitted: 08/13/07

Resubmitted: $12 / 02 / 10$

References \& notes: 58

Word count: 9626

Tables: 1

Figures: 2 


\begin{abstract}
Naïve theories of behavior hold that actions are caused by an agent's intentions, and the subsequent success of an action is measured by the satisfaction of those intentions. But when an action is not as successful as intended, the expected causal link between intention and action may distort perception of the action itself. Four studies found evidence of an intention bias in perceptions of action. Actors perceived actions to be more successful when given a prior choice (e.g., choose between two words to type) and also when they felt greater motivation for the action (e.g., hitting pictures of disliked people). When the intent was to fail (e.g., singing poorly) choice led to worse estimates of performance. A final experiment suggested that intention bias works independent from self-enhancement motives. In observing another actor hit pictures of Hillary Clinton and Barack Obama, shots were distorted to match the actor's intentions, even when it opposed personal wishes. Together these studies indicate that judgments of action may be automatically distorted, and that these inferences arise from the expected consistency between intention and action in agency.
\end{abstract}

Word count: 186

KEYWORDS: Intention, Action, Self-enhancement, Perceptual Distortion 


\section{Action Embellishment: An Intention Bias in the Perception of Success}

The perceived link from intention to action in human behavior is a fundamental aspect of social cognition, and has repeatedly captured the attention of researchers interested in the naïve psychology of action (Heider, 1958), the intentional stance (Dennett, 1987), the folk concept of intentionality (Malle \& Knobe, 1997) and theory of mind (Premack \& Woodruff, 1978). The crux of these lay theories is the expectation that intentions cause actions, and moreover that stronger intent should result in more successful actions. Unfortunately, people often fall short of this ideal. Our lives are polluted with countless typos, pratfalls, botched parallel parking attempts, and many other instances where actions do not live up to our ambitions. But when best laid plans go awry, the expectation of consistency between intention and action may blind people to the true extent of their failure. In this research we suggest that such an intention bias can result in distorted perceptions of action. The success of observed actions may be embellished above actual performance, to be consistent with the strength of the underlying intention.

\section{Intention as the Cause of Action}

An old adage warns the road to Hell is paved with good intentions. The inherent irony in this proverb is the violation of common sense causality: good intentions ought to lead to good outcomes. It is this expectation that leads students study hard for exams because they think it will result in a better grade, or for athletes to visualize success before an important play. The relationship inferred between intentions and actions is more than an association of similarity - it is the basis of a specialized attribution system 
commonly applied to agents (Wegner, 2002). An agent is an entity that moves by selfpropulsion (e.g., humans, animals, robots), in contrast with inanimate objects that move only by external physical force (Michotte, 1963; Molina, Van de Walle, Condry, \& Spelke, 2004). In other words, an agent is its' own cause, or a "first cause". But the ultimate source of action is seen as the intention to act: agents move because they want to, toward some desired outcome (Repacholi \& Gopnik, 1997).

Like other kinds of causal judgments, agency judgments are often snap decisions that occur spontaneously and effortlessly (Hassin, Bargh \& Uleman, 2002), suggesting automatic processing (Bargh, 1994; Uleman 1999). As noted by Guthrie (1993), the automaticity of agent detection is an important evolutional advantage - in identifying who might be potential enemies, friends, mates, predators, or prey. The mere appearance of self-propelled movement in a target is often enough to prompt attributions of agency (Premack, 1990; Morewedge, Preston, \& Wegner, 2007), especially if the end state of movement appears to satisfy some goal (Heider \& Simmel, 1958; Csibra, Gergely, Biro, Koos, \& Brockbank, 1999). Apparent symmetry between one’s own intentions and actions also cues judgments of agency in the self, reinforcing feelings of conscious will over own behavior when it seems consistent with a prior intention (Wegner \& Wheatley, 1999; Dijksterhuis et al, 2008).

Yet at times this equation between intention and action appears incomplete, either because the actor's intention is unknown or the action is ambiguous. In such cases, an observer can reconcile the two by adopting a model of ideal agency (Wegner, 2002; Preston \& Wegner, 2005). In an ideal agent, intentions always translate perfectly into action and actions always satisfy prior intention. Expected consistency between intention 
and action may help to fill in occasional "blind spots" by matching what is missing to what is observed: creating a prior intention to explain action, or distorting the perception of action to align with intention. For example, watching another person performing an action (e.g., roommate scrubbing the floor), may instantly prompt thoughts of underlying motivation consistent with that action (e.g., to impress a coming houseguest) (McClure, 2002). The ability to instantly mind-read the invisible mental states of others proves to be an essential social skill (Baron-Cohen, 1995; Sacks, 1995), as people do not usually publicize their intentions before action, like calling shots in a pool game. Fortunately, inferences of intention can occur automatically (Hassin, Arts, \& Ferguson, 2005), which allows one to quickly make sense of social interactions as they happen, and to respond in a timely fashion.

Efficiency gained in automatic judgments of intention is sometimes at the expense of accuracy, however, and these mistakes are often in the direction of aligning intentions and actions together. For example, outside observers tend to see others' actions as internally motivated, and largely ignore the influence of external factors that constrain behavior (Gilbert, Pelham, \& Krull, 1988). Observers also tend to interpret others' behavior as approach motivated toward the obtained outcome, even when the true motivation was to avoid another, undesirable, outcome (Miller \& Nelson, 2002). Interestingly, similar mistakes can also be made in judging own intentions. Early hypnosis studies showed that subjects would explain odd behaviors triggered by posthypnotic suggestion by generating a (sometimes equally unusual) prior intent (Moll, 1888). Cases of split-brain patients who have had their corpus callosum severed, and so have no communication between left and right brain hemispheres, provide some vivid 
examples of confabulating intentions for actions when they cannot access the true reason for behavior (Gazzaniga, 1988; Gazzaniga \& LeDoux, 1978). For instance, one splitbrain patient giggled in response to a nude picture shown only to her left visual field, but she told the experimenters she laughed because "the machine was funny". Although she did not really know why she laughed, she quickly concocted a reason that made sense and accounted for her behavior (Gazzaniga \& LeDoux, 1978). Evidence from the cognitive dissonance and self-perception literatures have also long shown that judgments of own attitudes (and the behavioral intentions they carry) can be altered post-hoc to be consistent with action (Wicklund \& Brehm, 1976; Bem, 1972). Most remarkable about these various confabulations is that they are almost always made with certainty and sincerity (e.g., Nisbett \& Wilson, 1977). Even when people observe themselves act without knowing why, they can concoct a prior intention that explains the behavior, seamlessly weaving the reasons for action into their ongoing personal narrative.

\section{Intention Bias}

Just as people show an action bias in judgments of intention, distorting prior intentions to correspond with observed behavior, they may also show the reverse error: an intention bias in judgments of action. For example, a tennis player could see the ball fall inside the line when everyone in the gallery sees it outside, or a person telling a joke could think it was a hit when everyone else thought it was a flop. Some evidence suggests that strengthening intention can embellish general estimates of action: although people tend to perceive themselves as above-average on a variety of qualities, these effects are exaggerated on those traits which are desirable and controllable (Alicke, 1985), and on traits that people judge to have an intentional component (Kruger \& Gilovich, 2004). 
Strengthening intention can also enhance predictions for future action, although it may not always translate into actual behavior (Koehler \& Poon, 2006). People become more optimistic about their gambling prospects as they become more involved in the process (Langer \& Roth, 1975; Risen \& Gilovich, 2007), or desire for success is particularly intense (Biner, Angle, Park, Mellinger, \& Barber, 1995; Thompson, Armstrong \& Thomas, 1998), both of which may contribute to a feeling of intentionality. Furthermore, when making a decision people begin to exhibit exaggerated positive illusions (unrealistic optimism about success of action) only after they finish deliberating about an action and have shifted to a post-decisional phase (Taylor \& Gollwitzer, 1995), i.e., they have decided on a plan for action and are preparing to put that plan into motion.

These findings suggest that strong intentionality can distort judgments of action in the past, future, or in the abstract. But because lay theories of intention-to-action causation may be inherent to human cognition, an intention bias may also work automatically to embellish perceived action. Yet there is little research to show that such distortion can occur in real time, as the action takes place. One likely reason is that these other forms of self-assessments are more ambiguous, and therefore benefit from the biased selection of memories, or idiosyncratic criteria that define success (Dunning, Meyerwitz, \& Holzberg, 1989). This is in sharp contrast to judgments made during the observation of the action itself. Often performance feedback is immediate and unforgiving (e.g., either the ball goes through the hoop or it doesn't). But even so, perception is rarely picture-perfect and is partially constructed by top-down processes that mold our experience to match beliefs and expectations (Pearson, Clifford, \& Tong, 2008). For instance, carrying a heavy load one one's back can make the slope of an 
upcoming hill appear steeper (Proffitt, 2006), but having choice over action reduces this effect, making distances and slopes seem more surmountable (Balcetis \& Dunning, 2007). Likewise, action itself may be distorted as it occurs if the actual success is unclear. Actions may be ambiguous because they happen quickly (e.g. plays in a baseball game), or the result is not immediately available for review (e.g., grade on a test). In such cases perceptions of actions may bend toward their intent, so that better actions should appear from stronger intentions. Because these judgments can occur automatically, one may never be aware of the distortion until corrected by the cold hard facts. But until such negative feedback is given, a fly ball may look like a homerun, a bombed test could seem like an ace, and if your good intentions should lead you straight to Hell- it could still look like Heaven when you get there.

\section{The Present Research}

In this research we predict that an automatic intention bias can distort the perception of action as it occurs. As intention to succeed increases so should perceptions of success, irrespective of actual performance. Four specific predictions were tested. First, factors that increase perceived intentionality (e.g. desire, choice) should result in action embellishment, distorting the perceived success above actual performance. Second, distortions should be consistent with the direction of intention: cases in which an agent's intention is to do poorly, perceived success should be diminished rather than embellished. For example, a tennis player who deliberately tries to throw a match may see the ball fall outside the line, when everyone else saw it fall inside. Third, the degree of distortion should correspond with the intensity of intentionality: actions executed with stronger intent should be embellished more than actions only weakly intended. Finally, an 
intention bias is separable from self-enhancement biases: distortions should extend beyond the self to actions performed by other agents. When the intentions of another agent are salient, the apparent success of action should be distorted to be consistent with the actors' intentions, irrespective of one's own personal desires.

In four studies, participants engaged in an activity (e.g., a typing task), or observed another engage in an activity, and reported the success immediately following each attempted act. In Experiments 1 and 2, intentionality was manipulated by the choice before action. In Experiments 3 and 4, desire for an outcome was used as an indicator of intention, specifically, the desire to hit a target picture of a liked vs. disliked person.

\section{EXPERIMENT 1: GOOD INTENTIONS}

Participants engaged in a typing study on a computer and reported estimates of typing accuracy throughout the task. For half the typing trials participants chose between two words to type, and on half the trials no choice was given. In pretests, we found word choice was associated with stronger feelings of intent to type the word. There was also a between subject factor of difficulty. In the difficult condition participants completed the typing task while wearing gardening gloves that made it more difficult to press individual keys. Greater embellishment was expected in this difficult version of the task for two reasons. First, increased difficulty is a detriment to performance, allowing more room for embellishment (Moore \& Healey, 2008). More relevant to the present hypotheses, the difficult task would require more effort, another indicator of intentionality (Bargh, 1994; Preston \& Wegner, 2007). The increased effort felt in the difficult version should enhance the perceived intention strength, and thereby further amplify perceived performance. 


\section{Method}

\section{Participants}

Ninety-nine participants were recruited by flyers in the Psychology department for $\$ 5$ payment.

\section{Procedure}

Participants were greeted by an experimenter and seated in front of a computer in a private lab room. All instructions were given on the computer. Participants were informed that a seven-letter word would appear on the computer screen, and that their job was to type the word as accurately as possible without looking at the keys on the keyboard. To prevent any temptation to cheat, the characters on the keys were covered by round yellow stickers. After each word was typed, participants estimated how many letters of the word they had typed correctly, from zero to seven, and entered this estimate into the computer. The specific scoring criteria were given to participants during the instructions, along with examples for each. Points were deducted if the participant missed a letter, typed an incorrect letter, had two sequential letters out of order, or for any extra letters typed. For instance, for the target word "OCTOPUS", 6/7 points would be given for mistakes such as: OCOPUS, OCTIPUS, OCTOUPS, or OCTOPUSS. Scores could not be lower than zero.

Using a mixed design, the task consisted of 100 typing trials. All participants completed 50 choice trials and 50 no-choice trials. On no-choice trials, a single sevenletter word was presented on the screen which subjects were asked to type. On choice trials, two different seven-letter words were presented side by side, and the participants chose which word to type. There was also a between-subject factor of difficulty. In the 
easy condition the task was to simply type a word on the screen without looking at the keyboard. In the difficult condition participants wore heavy gardening gloves as they typed, which made it more difficult to press individual keys. All words were presented in 24 point Garamond type, and remained displayed on screen as the participant typed. No feedback about the success was given to participants. After typing the word, participants pressed the enter key to proceed to the next trial. Two orders were used: no-choice/ choice; choice/ no-choice, randomly assigned at the beginning of the study. The sequence of trials within each section was randomly generated.

Results

\section{Difficulty}

Mean scores for perceived and actual typing accuracy was calculated for both choice and no-choice trials. The difference between participants' perceived performance and actual performance on a given typing trial represented the degree of distortion for that trial. Using these means a 2 (Choice) $\times 2$ (Distortion: Actual vs. Perceived typing) $\times$ 2 (Difficulty: Easy vs. Difficult) $\times 2$ (Order) ANOVA was conducted, with repeated measures on the first and second variables. There were no main effects or interactions with $O r d e r$, so we dropped this variable from further analyses and conducted a 2 (Choice) x 2 (Distortion) x 2 (Difficulty) ANOVA. There was a robust effect of difficulty condition, $F(1,97)=135.69, \mathrm{p}<.001, \eta_{\mathrm{P}}{ }^{2}=.58$, such that both actual and estimated performance were lower in the difficult version. In addition, there was a two-way interaction between distortion and difficulty, $F(1,97)=61.64, \mathrm{p}<.001, \eta_{\mathrm{P}}{ }^{2}=.39$, with greater positive distortion in the difficult version vs. the easy version. That is, participants in the difficult condition embellished their typing performance $\left(M_{\text {actual }}=2.14, S D=1.65\right.$; 
$\left.M_{\text {report }}=3.36, S D=1.72\right)$ whereas participants in the easy condition underestimated performance $\left(M_{\text {actual }}=6.64, S D=1.11 ; M_{\text {report }}=5.54, S D=1.60\right)$. This is consistent with previous research demonstrating greater embellishment for difficult tasks (Moore \& Healy, 2008). Further, difficult tasks require more effort and attention to execute which also denotes intention strength. Consistent with our hypothesis, expending these resources could lead to embellished perceptions of performance relative to the actual success of the action.

\section{Choice}

Our principal hypothesis that choice would increase embellishment was supported by a two-way interaction between Distortion and Choice, $F(1,97)=11.13, p=.001, \eta_{\mathrm{P}}^{2}$ $=.10($ see Figure 1$)$. Typing estimates for the choice trials $(M=4.53$ letters; $S D=.20)$ were significantly greater than both the typing estimates for no-choice trials $(M=4.37$, $S D=.25 ; F(1,97)=10.87, p=.001)$, and actual typing performance on choice trials $(M$ $=4.25, S D=.26 ; F(1,97)=4.69, p<.05)$. In other words, participants thought they typed better when first given a choice versus no choice, and this perceived success on choice trials was embellished above their actual performance. Despite this perception, choice did not improve actual performance $\left(M_{\text {choice }}=4.25, S D=.26, M_{\text {no-choice }}=4.31, S D\right.$ $=.20 ; F(1,97)=1.30, n s)$. This predicted effect of Choice on distortion held up for both the easy version $\left(F(1,46)=6.34, p<.05, \eta_{\mathrm{P}}{ }^{2}=.12\right)$ and the difficult version $(F(1,51)=$ 4.56, $\left.p<.05, \eta_{\mathrm{P}}^{2}=.08\right)$. This embellishment was not observed on no-choice trials, estimated performance was consistent with actual performance $\left(M_{\text {perceived }}=4.37, S D=\right.$ $\left..25 ; M_{\text {actual }}=4.31, S D=.20, F<1\right)$. 


\section{Discussion}

In Experiment 1, both increased choice and increased difficulty resulted in positive distortions of action. First, task difficulty contributed to embellishment. Those who participated in a difficult version of the task (typing with gloves on) overestimated their performance relative to actual performance, whereas those in the easy version (no gloves) underestimated performance. One possible reason for this interaction with difficulty is that they are due to an effect of regressive judgments when feedback is ambiguous. In other words, when actual accuracy is quite low (high difficulty condition), people will make greater estimates, but when actual accuracy is quite high (low difficulty condition), estimates tend to be lower (e.g., Fiedler, Walther, \& Nickel, 1999). However, these results could also be explained by embellishment effects, consistent with our hypothesis. Difficult tasks require more effort, which also indicates intention strength. The difficulty experienced in the task might increase embellishment by increasing the exertion put into the action. But more important than the effect of difficulty condition, we observed a strong effect of choice on embellishment. As predicted, participants overestimated their typing performance when they had been given a choice between two words to type, but did not embellish their performance in the absence of choice. And although participants believed they were better typists when given a choice, in reality they typed equally well without the choice. In sum, the results of Experiment 1 provide initial evidence that people embellish actions consistent with an intention bias.

\section{EXPERIMENT 2: BAD INTENTIONS}

In Experiment 1, choice prior to action led to inflated perceptions of action. An alternative interpretation of this result is that it reflects a self-serving distortion (Miller \& 
Ross, 1978), and so might be explained by a need to feel good about the self (Taylor \& Brown 1988). Experiment 2 addressed this question by attempting to reverse this effect — causing people to diminish performance, rather than embellish, if they intended to fail, rather than succeed. Ordinarily people do not try to fail, but there are certain circumstances under which people might deliberately sabotage their own actions. For example, a professional athlete might be bribed to take a dive in an important sporting match, or a reluctant law student might try to bomb the LSAT to avoid entering the family business. If actions are embellished when intention to succeed is high, then by the same token actions ought to be diminished when trying to fail. In Experiment 2, participants recorded themselves singing two brief excerpts from pop songs; but they were told the goal was to sing as poorly as possible. We expected that choice would result in exaggerated perception of the action to match their overall intention, in this case, that their singing performance will seem worse than actual performance.

\section{Method}

\section{Participants}

27 undergraduates (9 men, 18 women) volunteered to take part in a voice sample study, for $3 \$$ payment or partial course credit.

\section{Instructions}

Participants were seated in a private lab room in front of a computer. The experimenter explained to participants that they would be asked to record their voice during the study on a tape recorder beside the computer, and were given instructions on how to use the recorder. Participants were then left alone in the room, and instructions were given on the computer before the task began: 
You will be asked to sing two short songs, and we will record your voice to be rated by other people at another time. There is a twist to this study: Your job in this study is to try to sing as BADLY as possible. Remember, the people who will listen to you later won't know you are trying to sing badly. So, please don't try to be funny or "cheesy" as you sing, just try to give a really poor singing performance.

Task

Participants sang two short excerpts from popular songs into the tape recorder; once with a choice of two songs to sing, once with no choice. The three song selections used were Billie Jean by Michael Jackson, You Give Love a Bad Name by Bon Jovi, and I'm Too Sexy by Right Said Fred. These songs were found in pretests to be familiar to undergraduate participants. In three conditions, each song was used once as the nochoice option, with the other two songs as the choice option. When participants were ready to sing, they began recording on the tape recorder and the computer provided the song lyrics on the monitor. The song excerpts consisted of two verses. Following each performance, participants were asked to rate the quality of own singing on an 11-point scale $(0=$ The absolute worst, $10=$ Perfect $)$.

\section{Results}

Two judges, blind to condition, listened to the participants' recordings and rated their performances on the same scale participants evaluated themselves $(0=$ The absolute worst, $10=$ Perfect). These two judges had an inter-reliability rating of $\alpha=.78$. The mean rating of the two judges was calculated for each performance. 
To assess whether subjects rated their own performance as worse, relative to judges, we conducted a 2 (Choice: none, choice) $\times 2$ (Rater: self, judge) ANOVA with repeated measures on the first variable. There were no main effects of Rater, $F(1,26)=$ $1.06, n s$, nor of Choice, $F(1,26)=1.89, n s$. But as predicted, there was a two-way interaction between Rater and Choice on evaluations of singing performance, $F(1,26)=$ $4.11, p=.05$ (see Figure 2). Participants gave lower ratings of their own singing when they chose which song to sing, compared to when no choice was given, $\left(M_{\text {choice }}=2.19\right.$; $\left.S D=1.06, M_{\text {no-choice }}=2.70 ; S D=1.54 ; F(1,26)=5.43, p<.05\right)$. In contrast, judges' ratings did not differ with respect to choice, $\left(M_{\text {no-choice }}=2.72 ; M_{\text {choice }}=2.78, F<1\right)$. Relative to the judges' ratings, participants underestimated their performance following choice, $\left(M_{\text {self }}=2.19 ; M_{\text {judge }}=2.78 ; F(1,26)=3.94, p=.06\right)$. When no choice of song was given, self ratings were consistent with the judges' evaluations, $\left(M_{\text {self }}=2.70 ; M_{\text {judge }}=\right.$ $2.72, F<1)$.

Preference for Song

Finally, we also tested whether there were any differences in participants' song choice, and whether this affected the participants ratings. When Billie Jean was forced and there was a choice between I'm Too Sexy, and You Give Love a Bad Name, no song was preferred over the other, $\chi^{2}(1, \mathrm{n}=7)<1, n s$. But when given the choice, Billie Jean was selected significantly more often $(\mathrm{n}=18)$ than either You Give Love a Bad Name $(\mathrm{n}$ $=1)$ or I'm Too $\operatorname{Sexy}\left(\mathrm{n}=1 ; \chi^{2}(2, \mathrm{n}=20)=12.8, p=.002\right)$. Given this clear preference for Billie Jean, it was important to rule out the possibility that our observed embellishment effects were driven by the more frequent selection of a difficult song. Two one-way ANOVA's confirmed that there were no significant differences in self- 
ratings across song choice, $F(2,24)=.435, p=.65)$, nor judge-ratings across song choice $(F(2,24)=1.352, p=.28)$ These results support the hypothesis that diminished perceptions of own performance were driven primarily by the act of choosing (rather than by particular song selection.

\section{Discussion}

The results show that choice can result in diminished perceptions of performance, if the actor's overall intention is to fail rather than succeed. Self-assessment corresponded with the judges' assessments when no choice was given, but when participants were given a choice of song to sing poorly they rated their performance more poorly than judges did. We can conceptualize these results as a mirror image of those from Experiment 1, with only perceived success following choice deviating from the other values. But whereas participants embellished their performance in Experiment 1, participants in this study perceived worse performance following choice when they had been trying to perform poorly. The fact that participants in the present study diminished their actions, rather than embellished, indicates that these distortions may be guided by the specific intention of the actor, not just a general bias towards positivity or success.

\section{EXPERIMENT 3: MiXed Motives}

In two studies actions were embellished to be closer to the intended goal when the actor was first given a choice prior to action. We have suggested these action embellishment effects result an expectation of consistency between intention and action. But choice is dichotomous — like a light switch is either on or off — and so it can be insensitive to the experienced intensity of intentionality which can amplify or dampen 
embellishment effects. In the present study, desire for a particular outcome was used as a measure of intention strength. Desire can be experienced at various intensities and so might better predict the degree of an observer's distortion. Also, whereas choice embodies key cognitive components of intentionality (e.g., the decision for action, and the identification of a specific goal), an agent's desire could be considered the "heart" of intentionality as it represents both the underlying reasons for action, and the motivation that drives them.

In a paradigm modeled after Rozin, Millman and Nemeroff (1986), participants in the present study engaged in a shooting task with a toy gun. The targets used were either well-liked people (e.g., Mahatma Gandhi) or extremely disliked people (e.g., Adolf Hitler). As in the study by Rozin and colleagues, it was expected people would be more motivated to hit disliked people vs. liked people. In this present experiment we made a new prediction: regardless of actual performance, perceptions of accuracy would change with the liking of a target. The effect of liking on actual performance was limited by making aim difficult to control. Consistent with their desire to do well, we hypothesized that people would embellish performance when the target was disliked.

\section{Method}

\section{Participants}

One hundred fourteen participants (62 women, 52 men) were recruited by flyers in the Psychology Department or through the Psychology subject pool. Participants received payment of $7 \$$ or course credit. 


\section{Stimuli and Apparatus}

We pretested several famous figures for familiarity and likeability, from which we selected 4 disliked figures and 4 liked figures as targets. The liked figures were Albert Einstein, John F. Kennedy, Martin Luther King, Jr., and Mahatma Gandhi. The disliked figures were Osama Bin Laden, Adolf Hitler, Saddam Hussein, and OJ Simpson. In a pretest there was a strong negative correlation between target likability $(1=$ dislike extremely, $7=$ like extremely $)$, and own intention to hit the target figure $(1=$ Do not intend, $7=$ Strongly intend), $r(64)=-.66, p<.001$.

A slide projector displayed the target faces onto a large piece graph paper with a grid of one-inch squares. All photos selected were black and white, in which the target person was facing forward and making eye contact with the camera. The projected image was $36 " \times 24$ ". The paper had a large florescent pink circle in the center to serve as the bull's-eye, which was centered between the targets' eyes. Participants fired at the target with a shotgun-style toy gun with foam bullets. After hitting the target, the bullets would fall to the ground. The toy gun used was a discontinued model, unfamiliar to participants, and difficult to aim with precision. ${ }^{1}$

\section{Procedure}

Before the experimental session began, participants gave liking ratings for all the target figures. For each target, participants first indicated whether they generally liked or disliked the person. If they disliked the person, degree of dislike was rated on a negative 7-point scale (-1 = dislike slightly, -7 = dislike intensely). If they reported liking the

\footnotetext{
${ }^{1}$ Difficulty in shooting was verified by one of the authors through extensive pretesting, in the name of science.
} 
person, they rated their liking on a positive 7 -point scale $(1=$ like slightly, $7=$ like intensely).

It was explained to subjects that their task was to try to shoot at a target, and to estimate their own performance after each shot. Participants faced a wall with a large graph paper with a grid of one inch squares, at a distance of ten feet away. In pretests, the grid on the target was not visible to participants at this distance. The experimenter (a research assistant blind to hypotheses) stood adjacent to the target area during the task and recorded the location of each shot on the grid as they occurred. Immediately following each shot, subjects estimated in inches how close they were to the bull's-eye of the target. Subjects were given 10 practice trials with no target face before the study began. A total of 96 trials were used, 12 trials per figure.

Results

One subject reported knowing OJ Simpson personally and was excluded from all further analyses, leaving a sample of 113 participants.

\section{Embellishment and Dislike}

Overall, the pretested liked figures were rated as more likable, $M=4.78, S D=$ 1.18 , than the pretested disliked figures, $M=-5.35, S D=1.22 ; F(1,112)=2756.46, p<$ .0001 . However, 27 of the 113 participants deviated from the majority opinion for at least one of the famous figures. The most controversial figures were OJ Simpson, who was liked by 11 participants, and John F. Kennedy who was disliked by 9 participants. In fact, for almost all the figures there was some deviating attitude among participants, with the sole exception of Adolf Hitler who earned unanimous reports of dislike. 
Mean actual and perceived accuracy were calculated for Liked (Gandhi, King, and Einstein) and Disliked Figures (Bin Laden, Hitler, Hussein). Because Simpson and Kennedy were so controversial among participants' ratings, we did not include them in these discrete categories. In the few remaining cases in which a person's preferences deviated from the majority, we used participant's own attitudes to create the categories of Liked and Disliked Targets. Using these means, we conducted a 2 (Liking) $\times 2$ (Distortion: Actual vs. Reported Marksmanship) ANOVA with repeated measures on the second variable. There was a main effect of Distortion, such that people generally overestimated their distance from the bull's-eye $\left(M_{\text {accuracy }},=6.16\right.$ inches, $M_{\text {report }}=6.78$ inches; $\left.F(1,112)=11.70, p=.001, \eta_{\mathrm{P}}^{2}=.10\right)$. It is unknown whether this overestimation of distance reflected a general modesty, however we expect it was due to a general miscalibration of distance. More relevant to our hypotheses, there was an expected twoway interaction between Liking and Distortion, $F(1,112)=7.24, p<.01, \eta_{\mathrm{P}}^{2}=.06$. Although actual marksmanship did not vary between disliked targets vs. liked targets, $(F$ $<1)$, people reported better marksmanship when firing at disliked targets $\left(M_{\text {disliked }}=6.57\right.$ inches; $\left.S D=2.31, M_{\text {liked }}=6.89, S D=2.73 ; F(1,112)=5.15, p<.05, \eta_{\mathrm{P}}{ }^{2}=.04\right)$.

\section{Degree of liking}

Using the categories of Liked and Disliked targets there was greater reported marksmanship toward the Disliked targets, consistent with our predictions. But more specifically, we were interested in whether the degree of embellishment would be influenced by intensity of liking or disliking. The intensity of attitudes toward the targets should correspond with intention to succeed. Thus, embellishment should increase as the target is hated more. Indeed, on average people gave their best ratings of marksmanship 
when shooting at pictures of Hitler $(M=6.45$ inches), also the most disliked figure on average $\left(M_{\text {like }}=-6.57\right)$. All eight targets were rank-ordered by mean liking. Using this rank order, reported distance, actual distance, and distortion were submitted to a repeated measures ANOVA using a linear contrast. The linear contrast was significant on reported distance, $F(1,112)=5.40, p<.05$, with better perceived performance for worse liked targets. Important however, there was no linear trend on actual distance, $F<1$. Perhaps more important, the distortion between actual and reported distance showed a significant linear trend, $F(1,112)=7.15, p<.01$. Mean judgments of marksmanship were distorted further from the actual hit as mean liking for the target increased (see Table 1).

Because individuals varied in their ranking and the intensity of liking/ disliking, it was important to take into account these differences by conducting a within-subject correlation between liking and distortion. Reported liking was re-coded to a 14-point scale, $(1=$ intensely dislike, $14=$ intensely like $)$. For each participant, the mean distortion between reported and actual distance was calculated for each of the eight targets. Correlations were conducted for each participant between these eight distortion scores and the individuals' reported liking, and then transformed into Fisher $z$-scores. Using a one-sample $t$-test, this mean correlation between personal liking and distortion was found to be significantly greater than zero, $r(113)=.12, p<.05$, with greater distortion towards hitting the bull's-eye as personal liking decreased. This correlation appeared to be driven entirely by the participants' reported success on the task, and not actual success. Using the same analyses, participants' liking for the target and their actual marksmanship were not related $(r=.04)$, but liking and reported marksmanship were 
negatively correlated $(r(113)=-.11, p<.05)$. Participants perceived better marksmanship as they personally disliked the specific target being hit.

Finally, we investigated the possibility that participant's liking for a target influenced their correlational accuracy (i.e., the correlation between actual and perceived marksmanship). In other words, while we have established that participants distorted their judgments of accuracy depending on how much they liked the target, it is also possible that participant's actual and perceived accuracy correlated differently across targets. Accordingly, the correlation between reported and actual distance was calculated for each target within each participant. Next, correlations between these 8 correlational accuracy scores and reported liking were computed (using the same 14-point liking scale as above). A one-sample $t$-test on the resulting mean correlation between correlational accuracy and personal liking was not found to be significantly different from zero, $r$ $(113)=-.003, n s$.

\section{Discussion}

In Experiment 3, desire for an action led to greater action embellishment. People perceived better marksmanship when aiming at disliked targets vs. liked targets. The degree of this distortion was also consistent with the reported intensity of liking/disliking. These results provide further evidence that an intention bias can distort the perception of action.

An alternative explanation for these results is that liking and disliking affected perception due to wishful thinking, unrelated to any causal theories of agency. It feels bad to see Gandhi get hit and better to see Hitler get hit - whether or not it is oneself 
doing the hitting. It is possible participants may have seen what they wanted to see, rather than what they intended to do. As noted by many philosophers, it can be tricky to separate desires from intention (Mele, 1988; Searle, 1984). And in this case, there is a natural confound between intention and preferred result. But this is not necessarily the case when one observes the actions of another agent. In Experiment 4, we try to disentangle the two by changing the target act to that of another person.

\section{EXPERIMENT 4: OTHERS' INTENTIONS}

In three studies, people embellished perceptions of their own actions when they felt greater intentionality. These studies provide support for an intention bias in judging actions, but to this point, judgments have been limited to the self's actions. Own actions might benefit from embellishment to a greater extent than others' actions, in part because there is an introspective advantage in knowing one's own (good) intentions (Kruger \& Gilovich, 2004). But if the intentions of another agent are well known, people should expect the same consistency between intentions and actions for that agent as they would for themselves - sometimes even contrary to personal wishes. In the present study, we examined whether an intention bias extends to the actions of other agents. In judging the actions of others, people should use that agent's intention as a cue. Actions should be embellished to match the intention of the actor, not the intentions of the self.

In this study, participants observed an actor throw a ball at two different targets: Hillary Clinton and Barack Obama, who at the time were in a highly publicized competition for the Democratic Party nomination in the 2008 U.S. Presidential election. Participants observed a video of an actor throwing a ball at pictures of Clinton and Obama over multiple trials, and were asked to estimate the accuracy of each throw. Half 
the participants were told that the actor was a Democrat who supported Clinton, and the other half were told he was a Democrat who supported Obama. We hypothesized that observers would see perceive the pitcher's shots to be closer to the target for the opposed candidate , (i.e., the Clinton supporter better at hitting Obama vs. Clinton, and vice versa for the Obama supporter) and further, this effect should be mediated by the perceived intention of the actor. Also important, this bias should emerge regardless of the observers' own political attitudes. When the intentions of the actor are clear, perceptions of action would be distorted by the perceived intent of the actor, rather than the wishes of the observer.

Method

\section{Participants}

Sixty-nine undergraduates (22 men, 47 women) participated in the study for partial course credit.

\section{Procedure}

All data was collected between January and March 2008, as senators Clinton and Obama competed in primaries for the Democratic Party nomination to run for President in the 2008 U.S. election. Participants were seated in front of a computer in a private room. Participants viewed a brief clip on the computer of a Caucasian male, who stated his political affiliation and voting intention for the 2008 Illinois Democratic primary presidential election. In the Clinton supporter condition the man on the video said he intended to vote for Clinton in the primary, in the Obama Supporter condition he said he intended to vote for Obama. After watching this clip, participants rated on 7-point scales the voting intentions of the actor $(1=$ Definitely Clinton, 7 = Definitely Obama $)$, and how 
much the actor intended to hit Clinton and Obama, respectively $(1=$ Not at all, $7=$ Strongly intend).

Video Judgments. Participants then watched 32 video clips of the actor pitching a ball at a picture of Hillary Clinton or Barack Obama, 16 shots per target. As in Experiment 3, the pictures were projected onto a wall, with a large red dot on the target's nose. All participants watched the same 32 clips, shown to participants in a random order. Marksmanship (distance to bull's eye) ranged from 1 - 12 inches, and clips for were matched on marksmanship for throws at Clinton and Obama, respectively. Immediately following each clip, participants estimated the distance of the shot to the target bull's-eye, in inches, to the nearest two decimal places.

Retrospective Judgments. After viewing all the video clips, subjects rated how well the pitcher hit Clinton and Obama, respectively, on two separate 7-point scales (1 = Very bad hitting Clinton/ Obama, 7 = Very good hitting Clinton/ Obama), and also how much the pitcher tried to hit Clinton and Obama, respectively $(1=$ Did not try, $7=$ Tried very hard). Finally, participants reported which candidate they personally preferred, and which party they expected to vote for in the 2008 election.

Results

\section{Pre-Task Judgments.}

Before watching the video, participants were asked to rate whom they believed the actor was going to vote for in the Democratic primary on a 7 point scale $(1=$ Definitely vote for Clinton, 7 = Definitely vote for Obama).Responses were analyzed by between-subjects ANOVAs. Participants in the Obama supporter condition believed that the actor was going to vote for Obama $(M=6.60, S D=.60)$ and participants in the 
Clinton supporter condition believed he would vote for Clinton $(M=1.67 S D=.92)$.

Judgments of actor intention to hit Clinton and Obama, respectively, were given immediately following the manipulation and prior to the distance judgment task, and analyzed by between-subjects $\mathrm{ANOVA}^{2}$. As expected, perceived intention to hit Clinton was stronger for the Obama supporter $(M=5.86, S D=1.33)$, compared to the Clinton supporter $\left(M=2.91, S D=1.84, F(1,66)=58.45, p<.001, \eta_{\mathrm{p}}{ }^{2}=.47\right)$, and perceived intention to hit Obama was stronger for the Clinton supporter $M=5.25, \mathrm{SD}=1.85$ ) vs. Obama supporter $\left(M=2.39, S D=1.52, F(1,66)=49.06, p<.001, \eta_{\mathrm{p}}{ }^{2}=.42\right)$. A single intention score was calculated by the difference between intention ratings, with greater scores indicating more intent to hit Clinton vs. Obama. Overall intention score was significantly different between affiliation conditions, $F(1,66)=68.99, p<.001 \eta_{\mathrm{p}}{ }^{2}=.51$. and correlated with predicted vote of the actor, Pearson's $r(68)=.73, p<.001$.

\section{Task Embellishment}

Perceived performance was assessed by judgments of distance to the bull's eye for each observed throw. We tested our central hypothesis that the actions would be distorted to according to the affiliation of the actor using a 2 (Target: Clinton/ Obama) $\times$ 2 (Actor Affiliation: Clinton/ Obama) ANOVA on distance scores, with repeated measures on the first variable. There were no main effects of $\operatorname{Target}(F(1,67)=2.36, p=$ .13), nor Affiliation $(F<1)$. Consistent with our hypothesis, the two-way interaction between Target and Affiliation was significant, $F(1,67)=4.21, p<.05, \eta_{\mathrm{p}}{ }^{2}=.06$. Task embellishment was defined as the mean difference between judgments, such that greater

\footnotetext{
${ }^{2}$ One participant did not complete items on prior intent, data analyzed using remaining 68 participants.
} 
scores indicate better perceived marksmanship on pictures of Clinton vs. Obama. The actor was perceived to be better hitting the bull's eye on Obama vs. Clinton when he was presented as a Clinton supporter $(M=-.05$ inches $)$, but worse hitting Obama vs. Clinton when presented as an Obama supporter ( $M=.36$ inches).

Retrospective embellishment.

After all clips, participants were asked to rate how well the pitcher hit Clinton, and Obama, respectively. Retrospective embellishment was defined as mean difference between scores, such that greater scores better marksmanship for Clinton vs. Obama. There was a main effect of Supporter condition on the retrospective judgments of performance, $F(1,67)=6.59, p<.05, \eta_{\mathrm{p}}{ }^{2}=.09$. Important, retrospective embellishment correlated with pre-task intention $r(69)=.37, p<.01$, and embellishment during the task, $r(69)=.30, p<.05$. Using linear regression, we found evidence that the main effect of condition on retrospective embellishment was mediated by judgments of intention before the task. When controlling for pre-task intention, condition did not predict retrospective embellishment, $\beta=.05, t<1, n s$, but intention significantly predicted retrospective embellishment when controlling for condition, $\beta=.34, t=1.93, p=.05$. As a test of mediation, a Sobel test was conducted on the regression of condition on intention, and intention on embellishment, Sobel $\mathrm{z}=2.86, p<.001$, indicating perceived intention before the task mediated the effect of condition on retrospective embellishment, see Figure 2. 


\section{Observer Preference}

Finally, it was important to examine whether the perceptions were affected by the viewer's own attitudes toward the targets. Overall $76 \%$ of participants favored Obama, $12 \%$ participants preferred Clinton, and $12 \%$ reported no preference. Because the preferences were highly skewed, we examined the perceived marksmanship towards the favored candidate and disfavored candidate (excluding the undecided participants). A repeated measures ANOVA was conducted on perceived accuracy for liked vs. disliked target according to own preferences. Own political preference had no effect on perceptions of accuracy $(F=1.83, n s)$. Including undecided participants, no correlation between own preference and the distortion difference between targets was found, $r(69)=$ $-.03, n s$.

\section{Discussion}

Experiment 4 found that intention bias extends to judgments of other agents' actions. When an actor was presented as a Clinton supporter, people thought he was better at hitting Barack Obama, whereas when he was presented as an Obama supporter, people thought he was better hitting Clinton. Also important, participants' own attitudes towards the candidates did not distort the perceived success of the actor. These results suggest that when the intentions of another actor are known, the other's actions are distorted to match that other's intentions, and are not distorted by one's own intentions and personal preferences. 


\section{GenERAL Discussion}

Like a pair of socks, intentions and actions should match. Consistent with this expectation, we found evidence in four studies of an intention bias towards judgment of action. These embellishments occurred for real-time judgments of success, resulting in a distorted perception of the action itself. Actions were embellished when the actor first had choice of actions, but not in the absence of choice (Experiment 1), and also when the motivation for success was high (Experiments 3 \& 4). In Experiment 2, participants were given a goal of failure (singing poorly), and success was exaggerated to seem worse than reality. This indicated that embellishment is not necessarily in a positive direction, but in the direction of intention. In Experiment 3, people reported themselves to be better at hitting targets they might want to hit (e.g. Hitler), compared to those they might not want to hit (e.g. Gandhi). Further, Experiment 3 found that the degree of embellishment corresponded with the intensity of intentionality. Perceived marksmanship toward a given target improved with greater personal dislike toward that target. In a final study (Experiment 4), it was found that observers distorted the actions of other agents consistent with an intention bias. Observers perceived another person to be better at hitting pictures that the actor disliked (Hillary Clinton or Barack Obama), even when it may have conflicted with the observer's own desires for the actor's success. These four studies indicate that an intention bias can automatically distort perceptions of action as it occurs, and that these inferences arise from the expected consistency between intention and action in agency. 
Issues and Limitations

\section{Alternative Accounts}

In Experiments 1 and 2, intentionality was manipulated by the choice of action. Consistent with predictions, choice distorted perceived action to be consistent with the intention - either better typing performance (Experiment 1) or poorer singing performance (Experiment 2). The use of choice as a manipulation of intention may suggest a cognitive dissonance account for the results, that the perceived outcome was distorted because participants were motivated to see their actions be successful. For example, dissonance research shows that people readily revise their prior attitudes (e.g., against raising tuition) to match their present behavior (promoting raising tuition), but that this revision is dependent on the appearance of free choice in their behavior (Festinger \& Carlsmith, 1959; Bem and McConnell, 1970). Experiments 3 and 4 help to address this issue, as these studies used the actor's desire rather than choice as a manipulation of intention strength. And in Experiment 4, participants judged the action of another agent, so dissonance should not impact perceptions. Though embellishments may sometimes enhanced by motivational biases, the intention bias described here is primarily a cognitive inference based on the expectation that intentions cause action. It is not clear, however, that a cognitive dissonance account should be inconsistent with an intention bias. Dissonance theory holds that people feel uncomfortable to have their thoughts and actions mismatched, and will alter whichever one is most ambiguous to match the other. Important, however, is the implicit assumption in cognitive dissonance theory that intentions and actions should match. As discussed above, the causal link 
between intention and action is so deep-seated in our social reasoning that it is often taken for granted. The revisions of attitudes (and the intentions associated with them) demonstrated in dissonance research may be part of this more general belief about the mechanics of ideal agency. More recent studies of cognitive dissonance have found that the orientation toward action is a critical factor in producing cognitive dissonance effects. For example, there is greater post-decisional spreading of alternatives when people first the actions that they will undertake (Harmon-Jones \& Harmon-Jones, 2002).

\section{Elements of Intentionality}

These studies focused on choice, desire, and to a lesser extent effort as measures of intentionality, but it is important to acknowledge the other components of intentionality not assessed here. Intentionality is not a single quality but a composite of several factors, including the desire for an outcome (e.g. wanting a sports car), beliefs about how to act to get the desired outcome, ("Sports cars can be obtained from car dealers in exchange for money"), and planning to act, (“Tomorrow I will buy that car!"). In addition, there are some necessary precursors for an act to be intentional - an agent must be aware of the action as it occurs, and also believe that the action will result in the desired outcome (Malle \& Knobe, 1997). Not all of these factors need to be present for an act to be judged as intentional, however, intentionality is enhanced as these mental states align (Malle \& Knobe, 1999). These various components of intentionality could be categorized into two kinds of causal forces on action: the reasons for action, and the mechanics of action. An agent's goal (the identification of a preferred outcome), desire (the particular valence of the goal), and beliefs (predictions of how action can accomplish goal) comprise the reason behind action - why the agent takes action in the first place. 
Conscious awareness and deliberate initiation of action may comprise the mechanics how the intention seems to create action. Because intentionality is not a discrete mental state but a composite of different mental states, we used two manipulations of intentionality that best converge on overall intentionality: the goal choice before action (Experiments $1 \& 2$ ), and motivation for success (Experiments $3 \& 4$ ). What is important here is that we should expect that additional elements of intentionality to have an additive effect on embellishment: as more factors are present, intentionality is strengthened, and embellishment is more likely. In general, we should expect more embellishment when there is greater premeditation, motivation, decision, and effort. Indeed, the division of these intentional components may be reason for the additive effects of choice and effort observed in Experiment 1.

Ability and expertise

Intentional actions must be produced by the abilities and skills of the agent, rather than a result of accident or luck (Malle \& Knobe, 1997). Therefore, the ability and expertise of the actor are important factors to that may impact action embellishment effects. The actions used in these studies were designed to be relatively easy to perform, but difficult to assess. We used tasks with somewhat familiar activities with novel variations, so that participants should be average in skill and low in expertise. In general we should expect more precise perceptions with expertise, as these individuals are more practiced and have may be a better judge of when they have performed well. Though expertise might be expected to moderate the degree of distortion, naïveté is not necessary for intention bias to influence perceptions of action. Even if judgments were more accurate in general, we may still expect to see distortions in the direction of intentions. 
Even experts can embellish actions when conditions are right, i.e. the result is ambiguous, and prior intent was strong.

Likewise, embellishments are not necessarily constrained by actual poor ability. Generally people believe themselves to be effective agents even when they are not, and overestimate their skills at various activities (Kruger \& Dunning, 1999). More relevant than one's true ability, are one's beliefs about ability and self-efficacy that suggest how well one can expect to enact their intentions (Rotter, 1966). Expectations are different for individuals who are depressed, have low self-esteem or feel outcomes are beyond their control (Bandura, 1977). Consistent with this reasoning, narcissists are more likely to commit extreme overestimates of competence (Ames \& Kammrath, 2004), but people with low self-esteem show reduced cognitive dissonance effects, that is they don't revise prior intentions following a counter-attitudinal action (Stone, 2003).

\section{Reality Check}

In a few of the studies presented here, the difference between conditions in the perceived success of actions was relatively small- for instance in Experiment 1, people in the choice condition embellished their typing performance by $1 / 4$ of a letter on average, and in Experiment 3, the perceived distance to the bull's-eye was less than a half-inch closer for the disliked target. These relatively small distortions raise the question: if action embellishment is possible, is it only in small amounts? Intentionality can distort perceived action, but perceptions of action are always anchored to the actual performance, and can only be embellished so far. In other words, reality has a confidence interval. The size of this interval is constrained by what we believe to be possible events, and the ambiguity of the action. While there may be no limit to how much we can desire 
an outcome, or the effort we put towards that goal, there is a limit to how far we can bend reality. A person may know that no matter how much he wants to or tries, he can't lift a car over his head, or jump to the moon, so it is unlikely that he will believe he has done so.

An extreme instance of action embellishment that exceeds the limits of rationality is found in the condition of anosognosia (also see: Kruger \& Dunning, 1999). Anosognosia results from stroke damage to the inferior parietal cortex of the right hemisphere (Bisiach \& Gemininani, 1991). As occurs in many strokes, patients experience some paralysis (in this case, on the left side of the body). But what distinguishes anosognosia from other conditions is that the patients don't believe themselves to be paralyzed. Instead they not only falsely believe that they could move their impaired arm if they wished, but also confabulate actions of the limb as though they are hallucinating - seeing themselves clap their hands together, or touch their nose with the paralyzed arm as it rests motionless at the patient's side. Important, the illusions of action associated with anosognosia appear to be independent of the actual physical impairment, and may extend to parts of the body unaffected by paralysis. In a key demonstration, one anosognosia patient was led to believe by a trick mirror that she was looking at her unparalysed arm when it was actually the reflected image of another person's resting arm. When she deliberately moved her own arm up and down, she again said she saw the limp alien hand moving up and down, just as she had previously falsely reported for her own paralyzed arm (Ramachandran, 1995). Ramachandran argues that the confabulatory symptoms of anosognosia result from damage to part of the right hemisphere responsible for "reality-testing", (Ramachandran \& Blakesee, 1998). While 
parts of the left hemisphere act as imaginative story-tellers, interpreting (and sometimes exaggerating) the perceived environment (Gazzaniga 1988), this region of the right hemisphere works as a kind of devil's advocate, questioning the plausibility of these interpretations. Anything that doesn't stand up to the scrutiny will be dismissed, even before a person is conscious of the thought. Without such a reality check patients with anosognosia are free to accept any confabulation they like, regardless of glaring evidence to the contrary.

The effects of action embellishment reported here represent an example of this phenomenon in a non-clinical population. People showed a distorted perception of the actual success - for example, the actual distance to a target seemed to grow or shrink in their eyes. It is possible that these minute distortions can be increased as time passes, and become the basis for later memory distortions and general evaluations. In the meantime, as action is observed, these minor distortions would pass a reality check because they are both consistent with expectations, and not far from the truth.

\section{Conclusion}

The success of any given action depends how well it brings about a desired outcome, or how closely it resembles the intentions of the actor. Unfortunately, such ideal agency is not always possible, and even the strongest intentions can fail to achieve a satisfactory action. In four studies it was found that action embellishment can result from an intention bias- the expectation that high intentionality leads to greater success. In maintaining an ideal perception of agency, success may be embellished to match intentions, distorting the very perception of action as it occurs. 


\section{Acknowledgments}

This research conducted with support from doctoral and postdoctoral fellowships from the Social Sciences and Humanities Research Council of Canada awarded to Jesse Preston. We thank Ricardo Alanis, Ashley Augustine, Marie Baldwin, Michael Berkowitz, Leanne Gaffney, Lucy Grayson, Devin Lyons-Quirk, Christine Mathieson, Linda Miller, Ari Moskowitz, and Ansel Witthaus for their assistance in data collection. We also thank Justin Kruger, Carey Morewedge, Jim Olson, Chick Judd, and three anonymous reviewers for helpful feedback from on an earlier draft of this paper. Correspondence should be addressed to Jesse Preston, University of Illinois, Department of Psychology, 603 E Daniel St, Champaign, IL, 61820. 


\section{REFERENCES}

Alicke, M.D. (1985). Global self-evaluation as determined by the desirability and controllability of trait adjectives. Journal of Personality and Social Psychology, 49, 1621-1630.

Ames, D. R., \& Kammrath, L. K. (2004). Mind-reading and metacognition: Narcissism, not actual competence, predicts self-estimated ability. Journal of Nonverbal Behavior, 28, 187-209.

Balcetis, E., \& Dunning, D. (2007). Cognitive dissonance and the perception of natural environments. Psychological Science, 10, 917-921.

Bandura, A. (1977). Self-efficacy: Toward a unifying theory of behavioral change. Psychological Review, 84, 191-215.

Bargh, J. A. (1994). The four horsemen of automaticity: Awareness, intention, efficiency, and control in social cognition. In R. S. Wyer, Jr., \& T. K. Srull (Eds.). Hillsdale, NJ: Erlbaum.

Baron-Cohen, S. (1995). Mindblindness. Cambridge, MA: MIT Press.

Biner, P.M., Angle, S. T., Park, J. H., Mellinger, A. E., \& Barber, B. C. (1995). Need state and the illusion of control. Personality and Social Psychology Bulletin, 21, 899-907.

Bisiach, E., \& Geminiani, G. (1991). Anosognosia related to hemiplegia and hemianopia. In Awareness of Deficit after Brain Injury; Clinical and Theoretical Issues, Eds. G. P. Prigatano \& D. L. Schacter. Oxford: Oxford University Press. 
Csibra, G., Gergely, G., Biro, S., Koos, O., \& Brockbank, M. (1999). Goal attribution without agency cues: The perception of "pure reason" in infancy. Cognition, 72, 237-267.

Dennett, D. C. (1987). The intentional stance. Cambridge, MA: Bradford Books/The MIT Press.

Dijksterhuis, A., Preston, J., Wegner, D. M., \& Aarts, H. (2008). Effects of subliminal priming of self and God on judgments of authorship. Journal of Experimental Social Psychology, 44. 2-9.

Dunning, D., Meyerowitz, J. A., \& Holzberg, A. D. (1989). Ambiguity and selfevaluation: The role of idiosyncratic trait definitions in self-serving assessments of ability. Journal of Personality and Social Psychology, 57, 1082-1090.

Fiedler, K., Walther, E. \& Nickel, S. (1999). The covariation principle in attribution: Not to be presupposed and not to be ignored. Personality \& Social Psychology Bulletin, 25, 607-622.

Gazzaniga, M. S., \& LeDoux, J. E. (1978). The integrated mind. New York: Plenum. Gilbert, D. T., Pelham, B. W., \& Krull, D. S., (1988). On cognitive busyness: When person perceivers meet persons perceived. Journal of Personality and Social Psychology, 54, 733-740.

Guthrie, S. E. (1993). Faces in the clouds: A new theory of religion. New York: Oxford University Press.

Harmon-Jones, E. \& Harmon-Jones, C. (2002). Testing the action-based model of cognitive dissonance: The effect of action-orientation on post-decisional attitudes. Personality \& Social Psychology Bulletin, 28, 711-723. 
Hassin, R. R., Aarts, H., \& Ferguson, M. (2005). Automatic goal inferences. Journal of Experimental Social Psychology, 41, 129-140.

Heider, F. (1958). The psychology of interpersonal relations. New York: Wiley.

Kruger, J., \& Dunning, D. (1999). Unskilled and unaware of it: How difficulties in recognizing one's own incompetence lead to inflated self-assessments. Journal of Personality and Social Psychology, 77, 1121-1134.

Kruger, J., \& Gilovich, T. (2004). Actions and intentions in self-assessments: The road to self-enhancement is paved with good intentions. Personality and Social Psychology Bulletin, 30, 328-339.

Langer, E., \& Roth, J. (1975). Heads I win, tails it's chance: The illusion of control as a function of the sequence of outcomes in a pure chance task. Journal of Personality and Social Psychology, 32, 951-955.

Malle, B. F. (1999). How people explain behavior: A new theoretical framework. Personality and Social Psychology Review, 3, 23-48.

Malle, B.F. \& Knobe, J. (1997). The folk concept of intentionality. Journal of Experimental Social Psychology, 33, 102-121.

McClure, J. L. (2002). Goal-based explanations of actions and outcomes. European Review of Social Psychology, 12, 201-236.

Michotte, A. (1963). The perception of causality (T. R. Miles \& E. Miles, Trans.). New York: Basic Books.

Miller, D. T., \& Nelson, L. D. (2002). Seeing approach motivation in the avoidance behavior of others: Implications for an understanding of pluralistic ignorance. Journal of Personality and Social Psychology, 83, 1066-1075. 
Miller, D. T., \& Ross, M. (1975). Self-serving biases in the attribution of causality: Fact or fiction? Psychological Bulletin, 82, 213-225.

Molina, M., Van de Walle, G. A., Condry, K., Spelke, E. S. (2004). The animateinanimate distinction in infancy: Developing sensitivity to constraints on human actions. Journal of Cognition and Development, 5, 399-426.

Moore, D. A. \& Healey, P. J. (2008). The trouble with overconfidence. Psychological Review, 115, 502-517.

Morewedge, C. K., Preston, J. \& Wegner, D. M. (2007). Timescale bias in the attribution of mind, Journal of Personality and Social Psychology. 93, 1-11.

Pearson, J., Clifford, C., \& Tong, T. (2008). The functional impact of mental imagery on conscious perception. Current Biology, 18, $982-986$.

Premack, D., \& Woodruff, G. (1978). Does the chimpanzee have a theory of mind? Brain \& Behavioral Sciences, 1, 515-526.

Preston, J., \& Wegner, D. M. (2005). Ideal agency: On perceiving the self as an origin of action. In A. Tesser, J. Wood, \& D. Stapel (Eds.), On building, defending, and regulating the self (pp. 103-125). Philadelphia, PA: Psychology Press.

Preston, J., \& Wegner, D. M. (2007). The eureka error: Inadvertent plagiarism by effort misattribution. Journal of Personality and Social Psychology, 92, 575-585.

Proffitt, D. R. (2006). Embodied perception and the economy of action. Perspectives on Psychological Science, 1, 110-122.

Ramachandran, V. S. (1995). Anosognosia in parietal lobe syndrome. Consciousness \& Cognition: An International Journal, 4, 22-51. 
Risen, J. L., \& Gilovich, T. (2007). Another look at why people are reluctant to exchange lottery tickets. Journal of Personality and Social Psychology. 93, 12-22

Ross, M., \& Sicoly, F. (1979). Egocentric biases in availability and attribution. Journal of Personality and Social Psychology, 37, 322-336.

Rotter, J. B. (1966). Generalized expectancies for internal versus external control of reinforcement. Psychological Monographs: General \& Applied, 80, 1-28.

Rozin, P., Millman, L. \& Nemeroff, C. (1986). Operation of the laws of sympathetic magic in disgust and other domains. Journal of Personality \& Social Psychology, 50, 703-712.

Sacks, O. (1995). An anthropologist on Mars. NY/London: Alfred Knopf/ Picador. Simons, D. J. \& Chabris, C. F. (1999). Gorillas in our midst: Sustained inattentional blindness for dynamic events. Perception, 28, 1059-1074.

Stone, J. (2003). Self-consistency for low self-esteem in dissonance processes: The role of self-standards. Personality and Social Psychology Bulletin, 29, 846-858.

Taylor, S. E., \& Brown, J. D. (1988). Illusion and well-being: A social psychological perspective on mental health. Psychological Bulletin, 103, 193-210.

Taylor, S. E., \& Gollwitzer, P.M. (1995). Effects of mindset on positive illusions. Journal of Personality and Social Psychology, 69, 213-226.

Thompson, S. C., Armstrong, W., \& Thomas, C. (1998). Illusions of control, underestimations, and accuracy: A control heuristic explanation. Psychological Bulletin, 123, 143-161. 
Uleman, J.S. (1999). Spontaneous versus intentional inferences in impression formation.

In S. Chaiken \& Y. Trope (Eds.). Dual-process theories in social psychology (pp. 141-160). New York: Guilford.

Wegner, D. M. (2002). The illusion of conscious will. Cambridge, MA: MIT Press.

Wicklund, R. A., \& Brehm, J. W. (1976). Perspectives on cognitive dissonance. Hillsdale, NJ: Erlbaum. 
Table 1.

Mean Actual and Reported distance to bull's eye by Target, Experiment 3.

\begin{tabular}{lcccccc} 
& \multicolumn{2}{c}{ Target Liking } & & \multicolumn{3}{c}{ Distance to Bull's eye (in inches) } \\
\cline { 1 - 2 } Target & Rank & Rating & & Actual & Reported & Difference \\
\cline { 1 - 2 } Martin Luther King & 1 & 6.70 & & 6.29 & 6.91 & -.61 \\
Mahatma Gandhi & 2 & 6.48 & & 6.10 & 6.89 & -.80 \\
Albert Einstein & 3 & 5.31 & & 6.10 & 6.80 & -.70 \\
John F. Kennedy & 4 & 5.15 & & 6.23 & 6.98 & -.73 \\
OJ Simpson & 5 & -4.56 & & 6.24 & 6.89 & -.65 \\
Saddam Hussein & 6 & -5.50 & & 6.04 & 6.58 & -.54 \\
Osama Bin Laden & 7 & -5.96 & 6.20 & 6.70 & -.50 \\
Adolf Hitler & 8 & -6.51 & 6.04 & 6.48 & -.43 \\
\hline
\end{tabular}

Note. Distance reported in inches, greater values indicate further distance from bull's eye. $N=113, * p<.05$, 
Table 2 .

Judgments of prior intention and retrospective success for pitcher's throws at Obama and Clinton, by condition, Experiment 4

\section{Condition}

\begin{tabular}{llllll} 
& \multicolumn{2}{l}{ Clinton supporter } & & \multicolumn{2}{l}{ Obama Supporter } \\
\cline { 2 - 3 } \cline { 5 - 6 } & Mean & $(S D)$ & & Mean & $(S D)$ \\
\hline Intention to hit Clinton & 2.94 & $(1.84)$ & & 5.86 & $(1.33)$ \\
Intention to hit Obama & 5.25 & $(1.85)$ & & 2.39 & $(1.52)$ \\
Retrospective success - Clinton & 4.03 & $(1.47)$ & & 4.69 & $(1.64)$ \\
Retrospective success- Obama & 4.39 & $(1.41)$ & & 3.86 & $(1.73)$ \\
\hline
\end{tabular}




\section{Figure Captions}

Figure 1. Actual and Perceived typing performance by choice, Experiment 1

Figure 2. Mediation between condition and retrospective embellishment by perceived intention of actor, Experiment 4. 
Figure 1

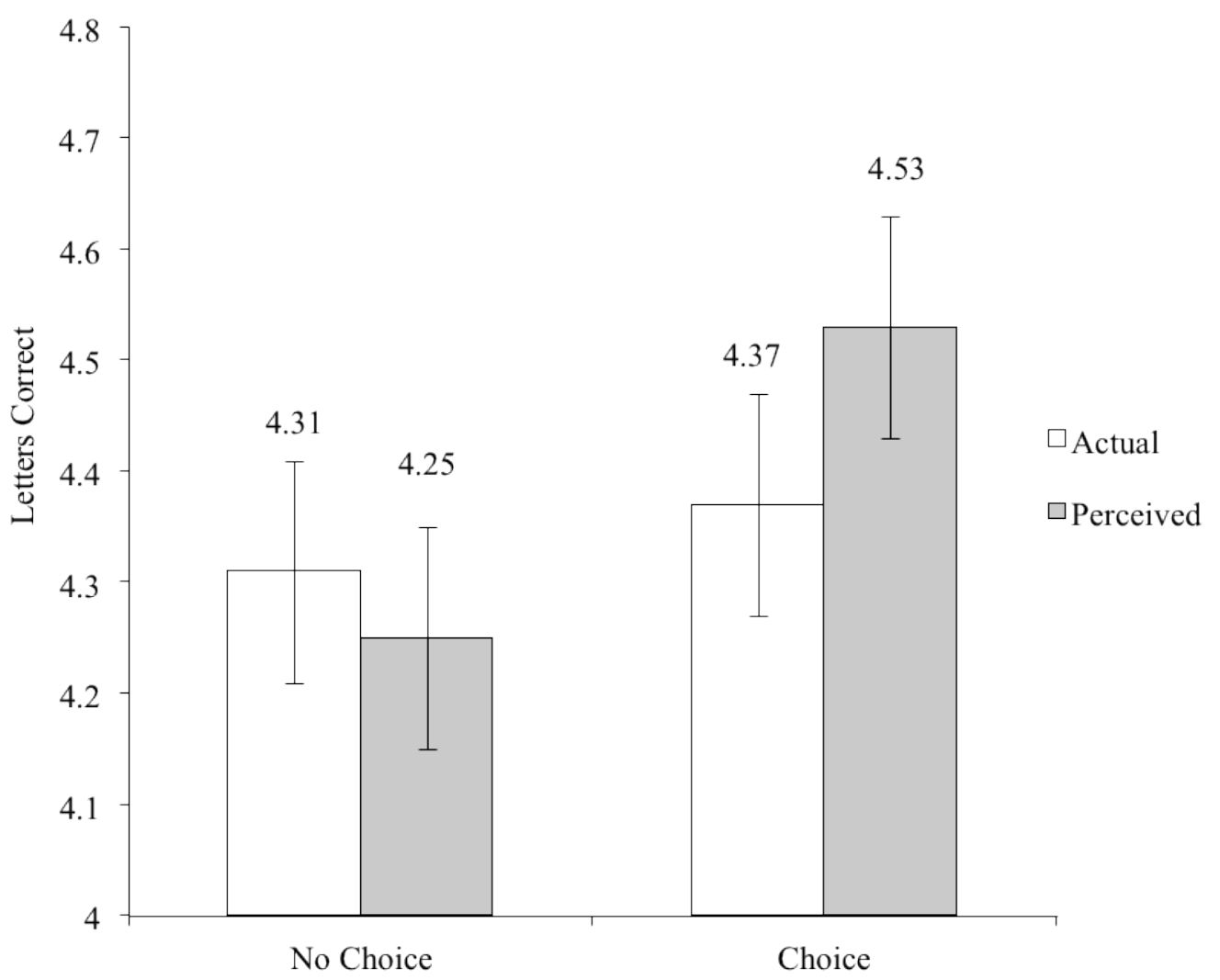

Words Available 
Figure 2

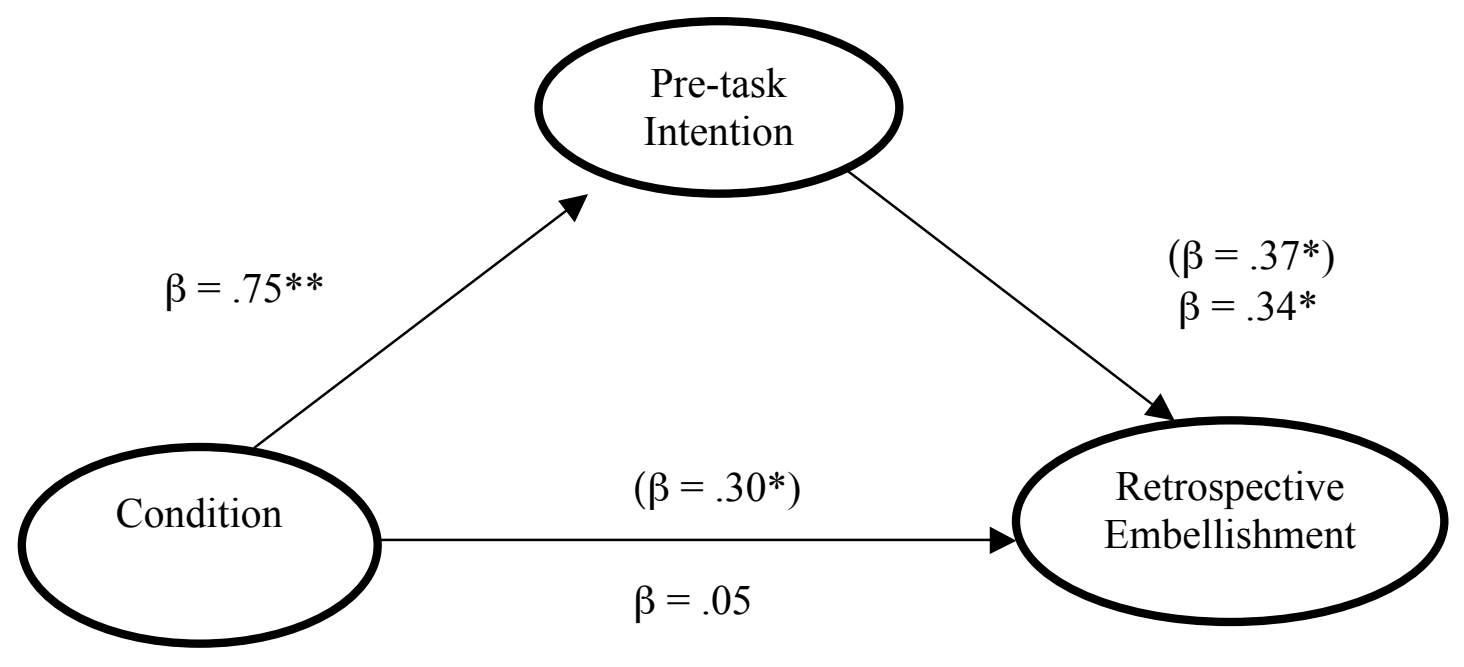

Note: Betas are standardized coefficients. Parenthetical coefficients represent direct effect of target speed and positivity with no mediator in the model. Asterisks indicate significant relations $(* p<.05, * * p<.001)$. 